\title{
The cultural other and the nearest neighbor: Han-Nuosu relations in Zhaojue County, Southwest China
}

\author{
Anke Hein ${ }^{\mathrm{a} *}$ and Deyun Zhao ${ }^{\mathrm{b}}$ \\ a University of Oxford, Institute of Archaeology, 36 Beaumont St, Oxford, OX1 2PG, United \\ Kingdom; bSichuan University, School of History and Culture, 29 Wangjiang Road, Chengdu, \\ 610064, Sichuan, P.R. China
}

Greater Liangshan is one of the few regions of China where, among $70-80 \%$ of Nuosu, the Han are a minority. Instead of the much more common phenomenon of 'Hanification,' here we can observe Han absorbing traits of other ethnic groups. Based on two seasons of fieldwork combined with historical texts and previous ethnographic research, this paper discusses this phenomenon, raising issues of ethnic identity and the influence of local circumstances on interethnic relations. Throughout the paper, it becomes clear that there is no simple dichotomy between Han and Nuosu, but that the situation is considerably more complex. The Nuosu fall into several castes, and the Han settlers had two different experiences. Some were captured as slaves and tried to become fully Nuosu. Ethnic relations in the Greater Liangshan are thus highly complex and require more research to be thoroughly understood. Keywords: Greater Liangshan; Nuosu; Yi; Han; ethnic identity; ethnic relations

\section{Introduction}

When discussing the 55 officially recognized ethnic minorities in present-day China, anthropologists and lay people alike usually lament their increasing 'Hanification' and the loss of their specific cultural traits; by contrast, cultural influences in the other direction are rarely mentioned, implicitly suggesting that they do not exist. This, however, is not the case. In the border regions of China, Han sometimes absorb traits of other ethnic groups or even completely change their ethnic affiliation. This rather intriguing phenomenon is evident in the Greater Liangshan Mountains 大涼山 in southwest Sichuan, where the Nuosu, or Yi 彞 族, as they are called by the Han, constitute $70-90 \%$ of the population, turning the Han from a majority into an - albeit dominant - minority. ${ }^{1}$

Choosing Zhaojue County 昭覺縣 as a case study, which together with neighboring Meigu County 美姑縣 has the largest concentration of Nuosu population in all of China (over 96\%), this paper investigates Han-Nuosu relations. The main questions raised in this paper concern issues of ethnic identity, varying attitudes toward the cultural other, and the influence of local economic, social, and environmental conditions on interethnic relations. Based on the results of two seasons of survey work combined with information from historical sources and geographic data, we suggest that the local Han population had two very different experiences: one group came forcibly as slaves and tried to become Nuosu as quickly as possible to better their situation; the other group came freely, taking advantage of their Han identity to help in negotiations between the Han and the Nuosu while simultaneously altering their behavior to match local lifestyles.

Considering the limited amount of fieldwork, these inferences are naturally preliminary in nature and require testing through further data collection, both in Zhaojue and in other parts of the Liangshan region. Nevertheless, this study already serves to show that the Greater Liangshan is a particularly fruitful study area for questions of interethnic relations and their geographic preconditions. Furthermore, in its own right this study contributes to the understanding of the cultural patchwork of the Liangshan region, and it provides a platform for general discussions on the nature of intercultural relations and various forms of identity. 
2. Geographic setting and historical and cultural background of Han-Nuosu relations

Zhaojue County is located in the eastern part of Liangshan Prefecture 涼山米族自治州, at the heart of the Greater Liangshan area, which lies east of the north-south-oriented Anning river 安寧河. Mountains dominate about $89 \%$ of the region, but the remaining $11 \%$ consists of river valleys and depressions (bazi 垻子) covered by fertile soil ideal for agriculture. The depressions of Zhaojue, Sikai 四開, and Sanwanhe 三灣河 are furthermore three of the largest expanses of land in the Greater Liangshan where the climate is mild enough for wetrice agriculture ${ }^{2}$; most Han therefore live here, while Nuosu settlements can be found mostly at higher altitudes. ${ }^{3}$

Technically, the Nuosu (or Ni, as they called themselves in the past) are only one of the groups officially classified as Yi minority by the government since 1956. The research area, however, is nearly exclusively inhabited by Nuosu, and for the local population the exonym $\mathrm{Yi}$ and the autonyms Nuosu and $\mathrm{Ni}$ are therefore synonymous. ${ }^{4}$ Throughout this paper, the term Nuosu is used to signal that all inferences to relations with the Han apply only to the Nuosu of the Greater Liangshan and not to Yi groups in other parts of Southwest China. At present, most Nuosu live in the Greater Liangshan but a significant number can also be found in other parts of Liangshan Prefecture as well as in Yunnan and Guizhou. The groups in Yunnan and Guizhou - with the exception of a group of Nuosu in Ninglang, Yunnan - are mostly described as Hanified, largely having lost command of their own idiom, Nuosu, while in the mountains of the Greater Liangshan many of the locals still speak their native tongue, in many cases even exclusively. ${ }^{5}$

The social structure of the Nuosu is often compared to the caste system in India, but unlike India there are no strict rules forbidding contact between the different castes among the Nuosu. ${ }^{6}$ Marriage between people from different social strata, however, is seen as impossible due to differences in 'bone'; the nobles are referred to as those of the black bone (or Heiyi 黑彝 in Mandarin) and the commoners as those of the white bone (Baiyi 白彞). ${ }^{7}$ There are five main castes; the upper two, i.e., the small top stratum of the nzymo and the nuoho are summarily referred to as black bones (Heiyi 黑彝 in Mandarin); the lower three strata of white bones are the quho (quhuo 曲伙 in Mandarin) or qunuo (曲諾), the mgajie (wajia 瓦加), and gaxy (gaxi 呷西). ${ }^{8}$ Gaxy are people recently captured or sold as slaves. It is possible for gaxy to rise to the level of mgajie or even quho after living with their capturers for a while and accumulating wealth and social acceptance. The barrier between black and white Yi, however, is usually considered to be impermeable. Mgajie or quho can fall in rank as low as gaxy through untoward marriage alliances, poverty, crime, or other circumstances, but a nzymo or nuoho only rarely sinks to the level of quho or below. Conversely, a quho can never become a nuoho, let alone a nzymo. ${ }^{9}$

These five main strata have various substrata and the actual standing of a particular person depends not only on his or her caste, but also on the clan, rank within the clan, and where he or she is from. In some areas, there are only nzymo and quho but no nuoho. Even more often, there are no nzymo or the local nzymo have sunk so low that they are in fact not more powerful than the local nuoho; nevertheless, even then the nzymo still receive the highest respect from all levels of society. The blood of the nzymo is seen as the purest, or rather their bones are the blackest, and they only reluctantly intermarry with the nuoho and even then only with those from the most powerful families. ${ }^{10}$

Besides social structure, what distinguishes the Nuosu and the Han are funerary customs and related ideas about ghosts. In spite of the ban on coffin burials since the 1950s, in rural areas Han usually bury their dead instead of cremating them, as they are afraid that the soul may otherwise have nowhere to return to and might come to haunt the living. The Nuosu, by contrast, always cremate their dead and are in fear of Han ghosts as the buried corpses - 
so they believe - may become a kind of vapor visible as phosphorescence light wafting over Nuosu land at night. ${ }^{11}$ Ghosts of people cremated properly are supposed to behave in a different way and are less fearsome to the Nuosu themselves, while the Han in turn do not seem to be troubled by Nuosu ghosts. The Han coming to live on their land thus has been a matter of great unease for the Nuosu since their earliest encounter with the foreign arrivals.

It is not clear when the Nuosu themselves moved into the Greater Liangshan area or when they first came in contact with the Han. Scholars, including Ma Changshou 馬長壽 and Stevan Harrell, rely on orally transmitted stories such as the Scripture for calling back the soul (Zhaohun jing 招魂經) and the Scripture of directing the way (Zhilu jing 指路經) when arguing that migratory movement occurred during the late Western Han ( $1^{\text {st }} \mathrm{c}$. BC).$^{12}$ Ma contends that during that time two lineage branches, the Gguhop (Guhou 古侯) and the Quxhniep (Qunie 曲涅), moved from Zhaotong 昭通 in Yunnan County toward the Greater Liangshan.

Other historians argue that the earliest migrants reached the Greater Liangshan during the Tang Dynasty (618-907 AD) ${ }^{13}$ Local leaders from the Liangshan region received land from Emperor Xuanzong 玄宗 (713-756 AD) after supporting him against the external forces of the Tubo 吐蕃 and the Kingdom of Nanzhao 南詔; these leaders, so Ma Changshou holds, may have been the ancestors of the Yi, as he calls them. ${ }^{14}$ Historical records indicate that the Nuosu had settled in the Greater Liangshan by the Song Dynasty (960-1279) at the latest. ${ }^{15}$ Several of our informants hold that most of the Nuosu clans now living in Zhaojue had come from Yunnan in the south, entering the Greater Liangshan 10 to 15 generations ago. Who lived in Zhaojue before the arrival of these clans is not completely clear. ${ }^{16}$

Under the Tusi system, the Yuan Dynasty (1271-1368) appointed local leaders of the nzymo or nuoho caste as tusi 土司 or tumu 土目 (usually translated as headmen or chieftains) who were meant to govern the region, ensure peace, pay tribute, and provide troops if requested. ${ }^{17}$ In the Greater Liangshan, the Yuan government established the dominion of the clan of the Luoluo Xuanweisi 羅羅宣慰司 (also referred to as Lili Tusi 利利土司) with its administrative center in Meigu 美姑 in the center of the Greater Liangshan. ${ }^{18}$ Later dynasties employed a bridle-and-halter (jimi 羁縻) policy toward the Greater Liangshan area, which was a self-administration system that appointed heads of local clans as local rulers while preserving a nominal claim on the region. In reality, however, the region was selfgoverned..$^{19}$ The so-called gaitu guiliu 改土歸流 under the Yongzheng Emperor 雍正帝 (1722-1735) led to the abolishment of the Tusi system in most parts of the empire, but in the Liangshan region the tusi remained in power. Here, the collapse of the Tusi system occurred only between the end of the Qing Dynasty (1644-1911) and the early Republican Period (1912-1916), following the upheaval of a confederation of nuoho. ${ }^{20}$

Toward the end of the Ming Dynasty (1368-1644), two nuoho clans expelled the Lili Tusi from Meigu. The tusi first moved to Xihewan 西河湾 in Zhaojue, but were banished by another alliance of nuoho clans to Xichang 西昌 in the center of the Anning river valley. ${ }^{21}$ The nuoho themselves were not a united force either and frequently fought each other. In the wake of these struggles, several nuoho clans left the Greater Liangshan, moving first to Xide County 喜德縣 and then through Mianning County 冕寧縣 and

Xichang into the Lesser Liangshan. ${ }^{22}$ After the Tusi system had collapsed in most parts of the area, apart from small local strongholds such as Leibo and Ganluo, many disunited family branches of Yi nuoho replaced local rulers instituted by the central government and the Liangshan region became increasingly ungovernable and inaccessible to outsiders. The 
Greater Liangshan became known as the 'Independent Luoluo' (Duli Luoluo 獨立羅羅), a region which the Han state forces could hardly enter. ${ }^{23}$

In the Greater Liangshan each nuoho clan preserved its own sphere of influence, and armed flights between clans were common. During the Republican Period, the main territories within Zhaojue were the following ${ }^{24}$ :

(1) the depression of Zhaojue, which was the territory of the nuoho clan of Bbaqit (Baqie 巴且);

(2) the depression of Zhuhe 竹核, east of Zhaojue, which was commanded by the nuoho clan of Ma 馬;

(3) the eastern part of the Sikai depression, which was dominated by the Ashuo 阿碩 clan, former tusi and nzymo who had intermarried with nuoho;

(4) the western part of the Sikai depression, which was the territory of the Ma clan, who were enemies of the Ashuo clan; and

(5) the area west of Sikai called Lanba 濫埧, which was the influence sphere of the Lynge (Er'en 爾恩) clan.

Travelers or merchants could not pass through the region safely unless they obtained the protection of those clans. The situation was particularly severe in the 1930s when people produced opium locally and the nuoho had funds to purchase firearms. Travelers wanting to trespass had to find a powerful nuoho clan and use money or wares to obtain their protection through a process known as zhao baotou 找保頭, 'searching for headprotection. ${ }^{25}$ The range of each arrangement, however, had spatial limits, and travelers had to find one protector after another until they arrived safely at their destination. ${ }^{26}$ The situation was similar for peddlers, but for them it was easier to obtain protection because they supplied wares that the Nuosu did not produce themselves, such as matches, thread, cloth, and agricultural implements. ${ }^{27}$

Apart from such trade arrangements, however, the Greater Liangshan remained inaccessible to the Han. In 1909, the Qing Government established a county seat in the area that remained in use during Republican Period. County magistrates, however, often were unable to reach their post, or if they did, their influence remained limited. During his survey in the 1930s, Ma Changshou learned from a former county magistrate that government decrees could not actually be implemented through his office alone, but that he needed the help and protection of the headmen of the Ma and the Baqie clan. ${ }^{28}$

For early Han settlers coming as private people without any government affiliation, the situation was different. According to previous surveys conducted in the Greater Liangshan in the 1930 to 1950 s, the first Han settlers likely arrived in the mid- to late $18^{\text {th }}$ century, mostly migrating from northeast Yunnan. ${ }^{29}$ At the time, the region was thickly forested and the Han prepared the land for large-scale agriculture. ${ }^{30}$ When famine broke out in Yunnan in the early 1800s, increasing numbers of Han streamed into the Greater Liangshan area, renting previously undeveloped land from the local tusi in Zhuhe, Zhaojue, Sanwanhe, and Sikai. These early settlers attained the status of kehu 客户 or qobo or qopbop (i.e., friends in Nuosu) of the local dominant clan, which afforded them a certain amount of protection against abductions and other forms of molestation. ${ }^{31}$ In exchange, the Han offered knowledge of a range of agricultural techniques and tools different from what was previously known to the Nuosu, as well as the use of their connections with Han from other regions for trade purposes. ${ }^{32}$ By the 1850 s, a substantial number of Han lived in the region as peasants engaging in handicraft and/or trade during the fallow season. ${ }^{33}$ 
Throughout this period, a number of historic events directly impacted the Han population in the Liangshan area. When a confederation of nuoho rose in 1852, they killed or expelled most of the Han who fled either back to Yunnan or to Jianchang 建昌 (present-day Xichang). The Provincial Governor of Sichuan sent soldiers to quell the rebellion, but once peace was restored only a few hundred Han remained. ${ }^{34}$ More local Han perished when the provincial commander of Guizhou led troops into the Liangshan region in 1868. Additionally, when an English missionary in Meigu Niuniuba 美姑牛牛坝 was killed in 1908, government troops conducted a punitive expedition that threw Zhaojue into chaos and led to even more Han deaths. ${ }^{35}$ The Baqie clan rose in 1920, destroying the county capital and killing over a hundred Han. When Ma Changshou came to Zhaojue in 1937, only three Han families lived within the city limits and five or six in the surrounding areas. ${ }^{36}$ In the case of Xiao Haiziba 小海子垻 in Zhaojue, which we surveyed, in the 1950s there were 11 Han households, of which at present only three are still represented by one or more households. ${ }^{37}$

Overall, Han settlements in the Greater Liangshan thus have a long and very eventful history alternating between cooperation with the Nuosu and fierce hostilities between the two groups, some of them government-induced, others caused by local power struggles. Our research project is particularly focussed on the nature of day-to-day interactions between Han and Nuosu in the context of these historical developments. To this end we conducted and will continue to conduct interviews with members of both groups living in the Greater Liangshan.

\section{Range of material and analytical approach}

Our ongoing research project started with a two-week survey in July 2013 at three locations in Zhaojue County: the communities of Heiluo 黑洛社 and Qieluo 且洛社 in Haogu Village 好谷村, Sikai 四開鄉, and Xiaohaiziba 小海子埧, a conglomerate of villages adjacent to the county capital of Zhaojue belonging to the administrative unit of Xincheng Town 昭覺 縣新城鎮, followed by a one-week survey in July 2014 in Liziping 李子坪 at the border of Zhaojue and Xichang. We selected Zhaojue County because the population is predominantly Nuosu (over 96\%) and approximately 3\% Han; at the same time, the area has yielded some of the earliest and strongest evidence of Han influence in Liangshan Prefecture. ${ }^{38}$

Furthermore, this region has been the object of relatively early ethnographic research, most remarkably the interviews conducted by Ma Changshou in the 1937, by Zeng Zhaolun in 1941, by Lin Yaohua in the 1940s, and by a team of research scholars in the 1950s. ${ }^{39}$ These surveys were not driven by specific research questions, though, but they concentrated on recording the history and customs of the group they identified as Yi. Since the 1980s in particular, much more research has been done, by Chinese, Nuosu, and Western scholars. ${ }^{40}$ In all cases, the focus has been on the situation of the Nuosu or other subgroups of the Yi and more rarely other non-Han groups in Southwest China. Even in studies that focus on interethnic relations, such as Stevan Harrell's highly insightful and multifaceted study entitled Ways of Being Ethnic in Southwest China, the Han remain a somewhat onedimensional cultural other coming from the outside. ${ }^{41}$ The Han that have been living among the Nuosu for many generations, however, generally find no mention. While relations between the different castes or social strata of Nuosu society have been much explored, the complex interactions between Nuosu from different castes and Han from different backgrounds are generally overlooked. This is a lacuna that this paper wants to fill.

To achieve this end, we conducted semi-structured and unstructured interviews with 22 individuals as well as 10 unstructured group interviews, combined with direct observation recorded through a combination of field notes, voice recording, video, and photographs. All 
interviewees were given the option to have their names, photographs, or other details omitted from the survey. Since clan and family bonds are important for understanding the local communities, in this paper we use real names when individuals gave consent and do not use aliases where consent was not given, but only mention the interviewee by ethnic affiliation, gender, and age.

For the first two seasons our fieldwork focused on elderly people in order to document change over time. We relied on lengthy interviews with them, as well as on conversations with their children and grandchildren, and interviews with their neighbors. Since the research team only speaks Mandarin Chinese and Sichuanese dialect, we required a translator for interviews in Nuosu. This applies to all interviews conducted with elderly Nuosu, including the individuals Ddisse Ditnjie (Diri Dingjia 迪日丁加 in Mandarin),

Latly Bburxqie 拉爾佈且 (La'er Buqie), and Ashuo Lathxa (Ashuo Laha 阿碩拉哈) mentioned in this paper.

We selected interviewees from a variety of social backgrounds. Most interview partners (85\%) were men because they were more approachable and more willing to discuss local politics, and more comfortable speaking Chinese than the majority of women. In future research, we anticipate longer stays in a specific village and/or multiple visits that will help remove some of the current barriers, enabling us to record a wider variety of voices on the chosen topic. Considering these limitations, the conclusions in this report are only preliminary in nature.

In our interviews we first asked about the situation of each individual and his or her family, inquiring when the family had first moved into the area and why, what life had been like at that point, and what they knew and thought about the presence of Han in the Greater Liangshan and their relationship with the Nuosu, both in the past and in the present. When inquiring into perceptions of the ethnic other, we mostly focused on a few major areas of life where we expected differences to clearly emerge, including food, clothing, housing, weddings, funerals, and other celebrations, as well as friendships, business, schooling, and other areas of daily interaction. However we also collected information on various Nuosu customs, especially activities of bimo 畢摩, religious specialists and keepers of Nuosu scriptures, and the state of mastery of Nuosu language and writing among young Nuosu.

For this paper, we decided to focus on five families who best represent the range of experiences of Han and Nuosu from various social backgrounds, their interaction with the ethnic other in day-to-day life, their perception of Nuosu-Han relations, and the history of the Han presence in the Greater Liangshan: two Han families who retained their Han identity to different degrees, one former Han family who tried their best to become Nuosu, and two Nuosu families, one of them of quhuo standing having particularly good relations with the Han, the other belonging to a nzymo clan that used to supply the tusi for Zhaojue. After introducing these five families, we discuss in detail our insights on similarities, differences, and areas of mutual influence in various aspects of everyday life, before suggesting preliminary inferences on the nature of Han-Nuosu relations in the Greater Liangshan.

4. The case studies: five families in Zhaojue

4.1 The struggle to remain Han: the Zhang family from Xincheng

To learn more about the Zhang family, we spoke with Zhang Zhicheng 張志成, a Han man of 89 years, former brigade cadre 大隊幹部 and Party Secretary 書記, his son and grandson, as well as two of his neighbors. All five of them speak fluent Mandarin, but when talking to his family and neighbors, Zhang Zhicheng seems to prefer using Nuosu. He himself declares 
that from childhood onward most of his outside communication was conducted in Nuosu while at home the main language was Mandarin.

According to Zhang Zhicheng's account, the Zhang family originally came from Tianjin, first moving to Chongqing, then Kunming, and then through Zhaotong to Zhaojue where they settled for at least 16 generations. The Zhangs thus arrived in Zhaojue during the time of the early Qing Dynasty (1644-1911). As far as our interviewees know, during that time there were no other settlers in the depression; this account is corroborated by survey material from 1937 placing the Zhang family arrival between the late Qianlong 乾隆 (17351896) and the early Jiaqing periods 嘉慶 (1796-1820). ${ }^{42}$ According to the same survey, in the late $18^{\text {th }}$ or early $19^{\text {th }}$ century a Han merchant from Yunnan named Zhang Zhaofu 張兆 福 frequently came to Zhaojue on business and eventually settled there.

Although Zhang Zhicheng insists that his family consisted only of farmers and masons ${ }^{43}$ but not merchants, previous surveys suggest that at least during the 1950s the Zhang family was still involved in trade activities. ${ }^{44}$ They were not itinerant non-local Han peddlers, however, but served as a link between these outsiders and the locals; the Zhangs thus had a considerably higher status than the foreign merchants. While the latter moved through the area by applying for protection of various clans whose territories they had to cross, the Zhangs remained stationary, enjoying a close connection with the nuoho clan of Bbaqit, being their kehu which afforded the Zhangs a certain amount of protection.

The Zhangs still have regular contact with members of the Bbaqit clan, and both sides visit each other on holidays, for weddings and funerals. Considering how strongly the Nuosu feel about the Han custom of burying the dead and the ghost that they believe may arise from this practice, this participation is rather remarkable. After all, participating means condoning, but as long as one did not adopt the practices of the cultural other for ceremonies in their own family - be it weddings or funerals - a consideration of alliances and good relations with the neighbors seem to have weighed more than such misgivings. Intermarriage, however, never took place. Zhang Zhicheng brags that the Bbaqit clan adopted the Chinese family name of Zhang, although no outside accounts corroborate this claim and the presentday ID cards of the Bbaqit clan do read Bbaqit, not Zhang. Nevertheless, the Zhangs were and still are afforded the privilege of a level of social interaction with the nuoho clan that is never granted to Nuosu from lower social strata, showing the rather high standing of the Zhangs in the local community.

In spite of these good relations, Zhang Zhicheng constantly expresses his low opinion of ethnic minorities in general and the 'Yi' in particular. Nevertheless, in the 1980s Zhang Zhicheng's oldest son married a Nuosu woman and states that at that time there was not much of a gap between Han and Nuosu, so that he intermingled freely with both. His 18year-old son proudly wears an earring in his left ear to signify his Nuosu identity and status as free quho, ignoring his grandfather's snide remarks. There thus seem to be significant differences between the experiences of these three successive generations; however, there are individual differences as well, as the case of Gao Shubi 高樹畢 shows.

\subsection{Transgressing boundaries: Gao Shubi and the girl with the pigs}

Gao Shubi, a Han man of 72 years of age, lives in Sikai Haogucun together with his Nuosu wife, his son, his Nuosu daughter-in-law, and their children. The Gaos are one of the old Han families as well, having come from Yunnan even before the Zhangs did, although when exactly is not quite clear. The family genealogy, which had first been written in Chinese characters and was later continued in Nuosu, was burned during the Cultural Revolution and Gao Shubi does not remember the details of its content. He does hold, however, that his 
family was never involved in trade but lived off farming millet, potatoes, corn, and rice, owning the majority of the rice paddies in the valley. They supported their farming income with small-scale home production of rice wine, as is

confirmed by earlier surveys in the region and accounts of other villagers. ${ }^{45}$

At present, the Gaos remain one of the wealthiest families in the valley and entertain close relations with the Ashuo clan, but apparently the relations with the Nuosu go much deeper than just an acquaintance with one of the leading clans. When Gao Shubi's oldest son became addicted to heroin, subsequently contracted HIV, and was sent to Xichang for treatment, other villagers helped him and his family in various ways, financially as well as with practical help and emotional support, suggesting a thorough integration of the Gaos into the Nuosu social network. Nevertheless, the Gaos retain their Han names, call themselves Han, and are described as Han by their neighbors.

Having served as a cadre for many years, Gao Shubi speaks very clear Mandarin rather than the local dialect usually heard among peasants. Although he grew up speaking Mandarin and declares that he speaks the same language with his children, during the interviews he sometimes had difficulties understanding questions posed in standard Chinese and immediately fell into Nuosu when talking to his family members or neighbors.

While his ancestors exclusively intermarried with other Han, Gao Shubi fell in love with a Nuosu woman who was guarding pigs on the roadside in Jiefanggou (located between Zhaojue and Xichang) while he was there on business. They got married with apparently little resistance from either family; nevertheless, a steep bride price of 400 RMB (now the equivalent of about $100,000 \mathrm{RMB})^{46}$ had to be paid, and the wedding was conducted according to Nuosu traditions.

Gao Shubi's wife moved to Sikai and they built a house combining an earthen wall structure with large wooden shingles in Nuosu fashion, with animal pens in the courtyard and a spirit altar for ancestor veneration in Han tradition. The altar, however, does not hold any spirit tablets and is used only twice a year for Chinese New Year and the Qingming Festival, i.e., the Tomb Sweeping Day. Remarkably, Gao Shubi is not quite sure about the meaning of these celebrations or which spirits he and his family are revering.

Gao family observations of Han holidays are overall rather idiosyncratic. For the Qingming Festival, they do not visit the graves as this holiday would demand but offer a pig's head on the altar as is common for Nuosu festivities. For his parents' funerals - both of them earthen graves according to Han custom and not cremation burials in Nuosu fashion - Gao Shubi called a Daoist priest from Xichang. For his own burial, however, Gao Shubi envisions an earthen burial with a coffin in Han tradition, but he wants to be buried with Nuosu headgear, thus displaying his complex ethnic identity.

\subsection{Becoming Nuosu: Yang Fanfan and his decedents through their neighbors' eyes}

It is difficult to identify Han who took on Nuosu names and tried to be integrated fully into the local community.$^{47}$ Some of our interviewees admitted knowing of such people but were not willing to identify them. The village head of Haogucun named one such person for us, but when hearing of our coming, this man preferred not to be available. Instead we spoke with his neighbors and former neighbors of his parents. Some of these interviews were conducted in Mandarin, some in Nuosu requiring a translator. As this person did clearly not want to be mentioned by name, here we will call him A. It is important to know, however, that he does not have a Chinese name but is only referred to by a Nuosu name.

According to the neighbors, A's father had been born in Xichang to a Han family, but at the age of eight or nine he was captured and became the slave of the wealthy quhuo family named Jjiexnuo (Jinuo 吉諾 in Mandarin). Consequently, the captured man and his 
decedents took on the last name of Jjiexnuo. His Han name was Yang Fanfan 楊帆帆, and all the villagers still refer to him by that name instead of using his Nuosu name, which we were not able to learn. When Yang Fanfan was captured, he did not speak Nuosu and had a difficult time fitting in, but he quickly learned the language and came to address his masters with the Nuosu terms for grandfather and grandmother. He played with the Nuosu children, but they report always having felt uneasy around him and having chaffed him more than other children.

Nevertheless, through hard work Yang Fanfan rose from gaxy to mgajie and was finally able to buy land. Finding a wife, however, was difficult, and he was only able to get married after the founding of the People's Republic in 1949 (referred to as jiefang 解放, liberation, by the locals) when he was already over 40 and his wife over 30 . She was Nuosu but also a slave, and she had a crippled hand, making it difficult for her to find a husband. She furthermore came from a poor village in the mountains, which made a match with a man from the fertile valley of Sikai desirable, even if he was of Han decent.

Yang Fanfan's status always remained low and when in the 1950s he had the opportunity to return to Xichang and find his relatives, he eagerly went. At that point, his parents and most of his other close relatives had already died. Furthermore, his own Mandarin had become very rusty and communication was much impaired. His former neighbors from Haogucun report Yang Fanfan commenting on the customs of the Han as strange. Not fitting in any more, Yang Fanfan thus returned to Sikai for good and - after his death - was cremated in Nuosu fashion, showing the completion of his transition to Nuosu ways of life even in the eyes of those he left behind - or at least in the eyes of his wife and children who arranged for the cremation.

Yang Fanfan had two daughters and one son, A. The son does not have a Chinese name and never learned Mandarin, refusing to acquire even the Sichuanese dialect. When 
being informed about our interest, he apparently became very angry, saying that he was not a Han, and fled our presence. Nevertheless, according to his neighbors, A is still not on equal footing with the Nuosu around him, being both a mgajie and of Han decent. Like his father, A had difficulty finding a wife. He only got married at over 30 years of age, to a mgajie woman from the same poor village his mother had come from. As his wife's ancestors had been captured many generations ago, her ethnic background is unclear, so she might be Han, Nuosu, or she might belong to an entirely different ethnic group. Yang Fanfan has three sons and two daughters. The daughters married Nuosu men, but likewise mgajie of limited means. They moved to Xichang, however, and were able to establish themselves in some business, thus rising in standing in the Han-dominated world but nevertheless remaining mgajie in the eyes of their fellow Nuosu.

\subsection{Godson of a Han family: Ddisse Ditnjie, the guardian of the bridge}

Ddisse Ditnjie is an 83-year old Nuosu man from a quho family. When he was young, he used to work as security guard for the county government and now serves as bridge guardian at the entrance to the county capital, Zhaojue. His family was classified as a 'rich peasant household,' preventing his appointment into higher ranks. He recounts 10 generations of his ancestors living in Zhaojue, making them newcomers in the eyes of the old Han families of Zhang and Gao, but nevertheless well established.

When Ddisse Ditnjie was a child, his family became acquainted with the Han family of $\mathrm{Mu}$ who at that point had been in the area for a few generations and was of relatively high standing, as both our informants and ethnographic surveys conducted in the 1950s testify. ${ }^{48}$ The families of Ddisse and Mu soon grew very close and Ddisse Ditnjie became the godson of the Han family. Periodically, Ddisse Ditnjie would eat at his godfamily's house, celebrated Han holidays with them, and swept the ancestral graves together with his Han sibling, apparently without succumbing to the great unease about Han ghosts common among the Nuosu. They communicated in Nuosu, for Ddisse Ditnjie never learned Mandarin and his adoptive parents - like many local Han of earlier generations - spoke Nuosu better than Chinese.

Ddisse Ditnjie's eight children, on the other hand, speak Mandarin fluently, and most of them have moved to large cities where they are in regular contact with Han. One daughter even married a Han, but in spite of continued good relations between Ddisse Ditnjie and his adoptive parents, the clan turned against his daughter and also against him and his wife for allowing the match. Ddisse Ditnjie does speak against such matches himself but says that in large cities dominated by Han it is difficult to avoid such close relations.

\subsection{The usefulness of the Han: under the protection of the Ashuo clan}

Keeping apart from the Han and lower-level Nuosu alike is naturally easiest in the remote mountains where the Ashuo are living. The Ashuo clan had long been the dominant power in Sikai. They are nzymo and provided the tusi for a while, having a considerable number of Han families under them. This changed when the Bbaqit clan (Bajie jia 巴且家) gained power because the Bbaqit belonged to the faction of nuoho that opposed the local Han presence. Consequently, the number of Han families quickly diminished under Bbaqit 
control. The Ashuo remained in the region and are treated with great respect until the present day, but they live in the mountains rather than in the river valley, keeping their distance from everyone else.

The oldest member of the Ashuo clan available for an interview was 59-year-old Ashuo Lathxa, who does not speak Chinese but was in the presence of his two daughters who helped translate his words. Ashuo Lathxa lives in a very large house built of clay and wood in traditional Nuosu style with one larger room, two smaller rooms, and minimal furniture placed directly on compacted soil with no intervening floorboards or tiles. The mere house size and the quality of the daughters' garments speak of the family's wealth, even if the material belongings displayed in the house are few.

According to Ashuo Lathxa, his clan originated from the area around Zhaotong in Northeast Yunnan and migrated to Zhaojue more than ten generations ago, i.e., sometime in the early $18^{\text {th }}$ century. During that period, the Lili clan was the dominant force throughout the Greater Liangshan. Since the Ashuo and Lili clans are related, the Ashuo moved from famine-stricken Yunnan to Sikai, replacing the Alei 阿勒 clan who previously had been the main local power. In the end, the Ashuo came to administer large parts of Zhaojue and Puge, thus becoming a major power in the Greater Liangshan. In fact, until today members of the Ashuo act as arbiters in conflict situations throughout the Sikai region and beyond, even though they lost absolute power first to the nuoho who then to the Han.

When the nuoho rebelled and took over the Sanwan River Valley, the Ashuo still retained enough influence to protect the major older Han families. According to Ashuo Lathxa, for his clan the presence of these Han was beneficial because of their knowledge of Han language and customs that allowed them to effectively protect local interests during negotiations with the encroaching Han. Similarly, during an interview conducted in the 1950s, Gao Yukun, a forefather of Gao Shubi declared that the Ashuo clan protected his family for various reasons. ${ }^{49}$ Firstly, the Gaos represented the Ashuo in negotiations with the Guomindang and were thus a useful ally. Secondly, the Gaos had family among the Han soldiers in Zhaojue, and the Ashuo were afraid that the military might take revenge if any harm befell the Gaos in Sikai. Furthermore, as Ashuo Lathxa mentions with a smile, the Gao family made good liquor and shared it freely with the Ashuo, making relations run smoothly. Intermarriage, however, remained out of the question.

Traditionally, the Ashuo clan only married other nzymo, but during the power struggles of the $19^{\text {th }}$ and $20^{\text {th }}$ centuries, the number of nzymo shrank and the Ashuo had no choice but to intermarry with high-ranking nuoho, mostly with members of the Bbaqit clan. Marrying a quho or a Han, however, remained inconceivable, even though the Ashuo retain friendly relations with the old Han families and interact with the quho as well. Apparently, there remain certain social and cultural gaps too wide to be crossed in this manner.

\section{Preliminary observations: similarities, differences, and mutual influence}

The brief description of the history and current situation of these five families clearly shows that there are considerable cultural differences but also similarities and mutual influences between Nuosu and Han living in the Greater Liangshan. The main realms in which all three phenomena can be noticed are eating habits; clothing and housing; 
weddings, funerals, and other rituals and celebrations; but also codes of conduct and interpersonal interactions.

As far as eating habits are concerned, the general topos is that Han eat with chopsticks and Nuosu eat with ladles, Han prefer rice and stir-fried dishes while Nuosu eat large chunks of boiled meat (called tuo-tuo rou 坨坨肉) as well as boiled potatoes, buckwheat cakes, and pickled-vegetable soup. The Gao family, however, seems to eat the same fare as their Nuosu neighbors, and Gao Shubi cannot remember his Han mother's cooking being much different from what his Nuosu wife serves. Nevertheless, his household uses chopsticks as well as ladles. The holiday feasts that Gao Shubi describes are also clearly dominated by Nuosu fare. The Zhangs, on the other hand, prefer rice and stir-fried dishes while the Nuosu in the mountains do indeed subsist mainly on potatoes, buckwheat, and boiled meat which they eat with knives and/or bare hands. In the river valleys, however, these days Nuosu can be observed eating Han-style food using chopsticks, saying that they prefer white rice over buckwheat if they can afford it. Generational differences, living locations, and wealth thus seem to be equally important in the choice of food and eating equipment.

The choice of specific clothes, on the other hand, is at least partially influenced by practical concerns as well. The vala or vapla, the warm and rain-resistant felt cloak of the Nuosu, is worn by both Han and Nuosu. Especially men of the older generation and people of all generations living in the countryside generally own such an item of clothing. Young men living in larger towns or cities where protection against the elements is less important, do mostly forgo making or purchasing such a cloak. Han men in all parts of the Liangshan, including even the much 'Nuosuified' Gao Shubi, never wear the wide pants or the headgear of the traditional Nuosu attire. Gao Shubi has Nuosu headgear at home, posed for pictures with it, and even wants to be buried with it, but he does not wear this headdress otherwise. The Nuosu Ddisse Ditnjie, on the other hand, immediately puts on his Nuosu headgear and exchanges his cigarette for a traditional pipe when he receives guests in his house. Otherwise, however, he remains clad in a washed-out blue Mao suit. These days only very few Nuosu men wear traditional garb in any case; only bimo and elderly highranking men, especially mountain-dwellers, are seen in such clothes. Nuosu women more often tend to wear traditional garments. All our informants mention this as one of the main differences between the two groups: Nuosu women wear skirts and Han women wear pants. While nowadays many Nuosu women wear pants, too, Han women never adopted the plaited skirt of Nuosu women. In general, Nuosu women living in the mountains and the countryside, especially in Nuosu-dominated areas, still wear traditional clothes, even though pants would be more practical for working in the fields. In Handominated areas and especially in larger towns and cities, however, both Nuosu men and women tend to wear Han-style clothing. They may avoid their clothes getting caught in machinery when working, but the wish to blend in with the Han population likely plays a role as well. One item of attire that can make at least the men rather recognizable is the single earring identifying the wearer as free-born Nuosu. While Zhang Zhicheng's grandson proudly wears such a ring in the Nuosu-dominated county capital of Zhaojue, young men going to Xichang, Chengdu, or other large cities for work or study usually take it out so as to be less conspicuous.

In cities, apartments of Nuosu and Han are largely the same, but in the countryside structures differ markedly between Han and Nuosu houses. Han families like the Zhangs 
usually live in multi-building courtyard houses with paved floors and various pieces of furniture such as chairs, tables, beds, cupboards, and even posters and clocks, as well as a spirit altar in one room. The animals are kept in pens, and the wealthier houses these days also have toilets and large kitchens with hip-high stove tops. The roofs of Nuosu houses are covered with wooden tiles and the animals are kept outside. The houses consist of one large main room entered from one long side and two small rooms on each narrow side. Even very large houses do not vary from this layout. The floors are unpaved and there is very little furniture. There is no separate kitchen, but a hole in the ground in the main room holds the fire for cooking and heating. Toilets are not common, the Han calling the Nuosu dirty for not having such facilities and the Nuosu considering the Han custom of having toilets in the house as unsanitary.

The mixture of both Nuosu and Han elements in the house of Gao Shubi and his wife is clearly a compromise between the two lifestyles, the layout of the house being in Nuosu style but combined with a spirit altar inside and animal pens outside. Young Nuosu with adequate financial means try to integrate Han house elements as well. The children of a bimo family living in the mountains of Zhaojue, for example, built a new house for their parents consisting of the one main room and four side rooms, but with the addition of a separate kitchen and a toilet outside in the courtyard. Additionally, the floor in the main building has been leveled with concrete and contains Western-style living-room furniture as it is popular in the Chinese countryside, i.e., a large couch, two armchairs, a couch table, a TV stand with TV, and a poster with flowers in bright colors. The parents, however, cannot get used to this new layout and prefer to stay in the old, traditional house in the mountains. Nevertheless, they do not call the living arrangements in the new house 'Han' but only modern and strange, likely because they associate them with their children and not with an ethnic group other than their own. As is the case with eating and clothing habits, the choice of house structure thus is influenced by generational differences, wealth, and place of living.

More lasting differences between Han and Nuosu emphasized by all our informants fall into the realms of wedding and funeral customs, holiday celebrations, the reception of guests, and general character and behavior. On the basic level, Han bury their dead and Nuosu burn them; Han have comparatively simple marriage customs and Nuosu follow a complex set of rules for weddings that include spending a considerable amount of money on bride price and celebrations lasting several days. These were the customs that Gao Shubi had to follow when marrying his Nuosu wife in the 1960s, while 20 years later the son of Zhang Zhicheng married his Nuosu wife without much ceremony, likely due to their living in the county capital with its significantly 'Hanified' ways and not in the countryside surrounded mostly by Nuosu. Again, location and generation make a difference, but individual factors may also play a part. The Gaos seem to be much more integrated into the local community than the Zhangs (as exemplified by the help the Gaos received from their Nuosu neighbors); furthermore, as both Gao Shubi and his son married Nuosu women, the Gaos are becoming increasingly more Nuosu not only their his day-to-day actions but also physically. Even Gao Shubi himself, although still a Han raised by Han, is considerably more Nuosu than Zhang Zhicheng, for instance. Although both are more comfortable speaking Nuosu than Mandarin and wear the vala, the Zhangs are still fully aware of the Han holidays and customs, while Gao Shubi's understanding of the meaning of Qingming and the spirit altar is only murky at best. His wish to be buried in Han fashion 
but with a token of his affiliation with the Nuosu world bears strong witness to his complex ethnic identity. It is remarkable, though, that he does not seem to fear becoming a Han ghost as the Nuosu envision them to emerge from unburned bodies, but is more concerned with preserving the body for the soul to come back to. When asked directly, Gao Shubi is not quite able to explain the ritual practices of his family, though, and his combining Han and Nuosu customs in a rather eclectic way is likely less a conscious act than a careful, partially intuitive navigating between two worlds. Lacking adequate data, it is currently not possible to ascertain whether this loss of the Han customs and 'nuosufication' is common among many of the old Han families or whether it is a particularity of the Gao family alone. It also remains to be seen how the customs and selfidentification of Gao Shubi's son and grandson, as well as of Zhang Zhicheng's grandson, develop and how generational, locational, and individual differences play out.

In any case, both the Zhangs and the Gaos show a considerable amount of adaptation to their Nuosu environment, as do other Han families in the Greater Liangshan. They speak Nuosu just as fluently as their Nuosu neighbors, and most aspects of their everyday life are rather similar, as all of our interviewees emphasize. Han and Nuosu kids play together, adults work together, neighbors help each other and visit each other for major holidays and celebrations. Nevertheless, Nuosu and Han alike still emphasize that they are two completely different groups of people with different mindsets. While the Han point out differences in wedding customs and lack of cleanliness in Nuosu households, the Nuosu emphasize the lack of decorum in the treatment of guests in Han households. In Nuosu households, guests are received with much courtesy that often includes butchering at least one chicken or even a pig or ox. Even when the host is extremely poor, guests are lavishly treated. Not surprisingly, most of our Nuosu interviewees express their disdain for the niggardly treatment of guests in Han households and the lack of ceremony at important festivities. Some also remark on the lack of obligation that Han feel toward their friends and neighbors; they apparently do not always help community members in need and often do not participate in community events, but are primarily concerned with their own family matters.

On the positive side, Nuosu and Han alike agree that Han tend to be diligent, hardworking, good at agricultural pursuits and handicraft, and also clever in business dealings, which allow them to have a higher standard of living than their Nuosu neighbors. The Nuosu admire Han industriousness and ability to budget recourses, but simultaneously characterize them as stingy and deceitful, while they describe themselves as honest and generous. ${ }^{50}$ Interestingly, also Ma Changshou and Zeng Zhaolun, although Han themselves, describe the local Han as particularly calculating. ${ }^{51}$ There are several possible explanations for this phenomenon. Their precarious situation between local Nuosu and foreign Han may have forced the local Han families to be particularly circumspect, making them seem calculating to both sides. It could also be that the local Han were not more thrifty than Han from other areas, but they may have seemed so compared with the nonchalant unconcernedness with money that the Nuosu exhibit.

The Nuosu themselves frankly admit that they tend to be wasteful, receiving guests with opulent meals and having sumptuous celebrations on major holidays, weddings, and other occasions with no thought about the next day or the next month. At least in the past, the Nuosu were not very interested in maximizing their income and looked down upon people earning their living as merchants. ${ }^{52}$ According to Thomas Heberer's research on 
Nuosu entrepreneurs in Southwest China, this seems to be changing as the Nuosu adapt to the pressure of a widening market. ${ }^{53}$ This, however, is a very recent phenomenon, and this movement is mostly carried by the lower levels of Nuosu society, while the nuoho and especially the nzymo still consider business dealings as below them.

They share this disdain for trade activities with members of the old local Han families whose elderly representatives emphasize that their forefathers never served as merchants. They also point out that they never paid tribute to the local nzymo or nuoho either, but were independent from both the Nuosu clans and the foreign Han merchants. Interestingly, the Ashuo corroborate this claim, saying that - in contrast to the later Han arrivals and the Nuosu of lower status - the old Han families did not have to pay tribute except for a symbolic bowl of grain each year and their participation in New Year rituals at the house of the Ashuo clan leader; this, however, may not be entirely true. According to a survey conducted in the 1950s, the kehu of the Ashuo clan were required to pay a tribute of $5 \mathrm{jin}$, i.e., about $2.5 \mathrm{l}$, of alcohol every year, and the Gaos and other Han families had to hand in $30 \%$ of their harvest. ${ }^{54}$ Unlike the lower-level Nuosu families, however, the old Han families did not have to give a pig's head to the leader of the Ashuo clan for the New Year, and they were also exempt from supporting the Ashuo in the blood feuds. In either case, both versions clearly show that the old local Han families have a status different both from the Nuosu and from Han merchants and later Han settlers. The interethnic or rather intergroup relations in the Greater Liangshan can therefore not be explained as a mere dichotomy between Han and Nuosu; instead, we see a complex network of relationships between Nuosu from various levels of society and various groups of Han whose living experience in the Greater Liangshan varies widely.

\section{Preliminary results and future work}

When arriving in the Greater Liangshan, Han immigrants encountered the highly complex social structures of Nuosu society and had to find their place, either within this system or outside of it. The Han themselves were not a homogeneous group either but arrived in several waves and under various circumstances. ${ }^{55}$ Firstly, there are the old Han families who arrived even before the Ashuo clan; secondly there are Han who were captured as slaves and became part of the Nuosu social structure; and thirdly there are the 'other' Han, the 'newcomers' who came later as traders or as officials appointed by the central government. The old Han families seem to have been rather wealthy and influential, owning large parcels of land and having close relations with the local Nuosu leaders. These Han thus had a higher status than the quho but were not completely on equal footing with the nuoho or the nzymo, for the Han still had to pay tribute (be it only symbolically or in more substantial sums) and were never seen as potential marriage partners. They adopted many local customs, their offspring soon speaking Nuosu fluently, often even better than Mandarin. Additionally, they were important negotiators in contacts with itinerant merchants, military, or officials sent by the central government, but also with new Han settlers.

Intermarriage between these old Han families and the Nuosu long seems to have been unthinkable for both sides. Only in recent years have an increasing number of such matches been seen, but never, it seems, between Han and the highest strata of Nuosu society, the nzymo and the nuoho who until today avoid marrying outside their own caste. The old Han 
families likewise used to intermarry exclusively among each other, keeping away from the Nuosu and preferring not to get too close to the newly arriving groups of Han either. This changed, however, when the number of Han dwindled due to local unrest; now also newcomers became eligible as marriage partners. Matches with Nuosu, however, are still abhorred by most elderly Han and Nuosu alike, the Nuosu regarding the Han as completely different in 'bone,' customs, and character, making such a match unthinkable.

Nevertheless, in certain respects the old local Han families have more in common with the local Nuosu than with outside Han. Similar to their Nuosu neighbors, the old Han families emphasize farming over trade and express their disdain for merchants. Fully fledged merchants can only be found among the 'newcomers,' who are still referred to as 'them' by the older generations of local Han families. Both local Han and Nuosu furthermore share local interests and are not in favor of outside intrusions. In the past, the old Han families could thus very well be trusted to represent the interests of the Nuosu in negotiations with foreign Han. To a certain extent, the old Han families are thus part of the local community, even though they remain outside of the Nuosu caste system and remain the cultural other. They are therefore a separate identity distinct from both other Han and Nuosu. It is also remarkable that - in spite of the topos of there being no intermarriage between the two groups - some Han men such as Gao Shubi seem to have married Nuosu women, and these women likely played a major role in their husbands' integration into Nuosu society. This question will require further research including extensive interviews with women.

What has already become clear, however, is that the old Han families have very little in common with Han that were captured as slaves. Coming alone, against their will, and often at a young age, the captured Han had no means and no interest in preserving their language and customs. By being captured, they automatically became part of the Nuosu caste system but entered it on the lowest rung. Adapting, through time and effort they could rise in society and become mgajie or even quho, quite independent of their ethnic affiliation. ${ }^{56}$ Nevertheless, when it came to finding marriage partners, newly captured Han and their children and grandchildren would still encounter difficulties. Customarily, Nuosu memorize at least 10 generations of genealogy and then recite them to each other to assess mutual relations and status, so it might take a while for the offspring of Yang Fanfan to be fully integrated in Nuosu society and find marriage partners without difficulty. Nevertheless, many of the younger villagers are not aware of the ethnic origin of this family, so at least in everyday life the grandchildren already have an easier time than their father or grandfather.

For Han captured as slaves, their Han identity was thus a burden and a hindrance that they wanted to make forgotten as fast as possible by becoming fully Nuosu in their behavior, language, and names. For the Han who settled as free men, being Han was associated with having a high status, even higher than free Nuosu, so they emphasized their Han-ness to a certain extent. Nevertheless, they also had to adapt to Nuosu society by building relationships with local leaders and commoners alike, and adopting Nuosu customs and language. From the point of view of the Nuosu, these Han never became Nuosu, but to non-local Han, these old Han families of the Greater Liangshan were not normal Han anymore either, making them a third kind of identity group that had a specific connecting function in Han-Nuosu relations. 
From the perspective of the local Han whose families had been in the area for 10 or more generations, the newly arriving Han remain 'the other,' even though technically they belong to the same ethnic group sharing a common language, but culturally they have drifted apart to a certain extent. Looking down on the new Han arrivals, the old Han families also despise certain qualities of the Nuosu, thus isolating themselves and being isolated in their own small world, connected with and yet separate from local Nuosu and outside Han alike. Their circle, however, is becoming smaller and smaller, younger generations moving away and/or intermarrying either with local Nuosu or Han from the outside world. If this trend continues, this very peculiar group of 'Nuosuified' Han may soon vanish completely and knowledge of the past of former Han slaves who became Nuosu will surely be lost as well. The preliminary results reached by our short surveys, combined with historical records and results of previous ethnographic work, highlight the great potential of the Greater Liangshan as a study area for questions of interethnic relations. Furthermore, it also becomes clear that much further research is needed to fully understand the cultural patchwork of this region in its own right, and that this research needs to be done soon before the groups discussed here cease to exist.

\section{Acknowledgments}

The authors are greatly indebted to the people of Zhaojue County for being so welcoming, inviting us into their homes, sharing food and drink with us, and talking to us extensively about their experiences and their views. We would especially like to thank Ebi Jiefang 俄比解放 who helped us to find interview partners in the first place, and who served as a translator and adviser on matters of Nuosu customs and culture. We are also very grateful to Erbu Shiha 爾布仕哈 for sharing his insights gained from many decades of ethnographic survey work in Liangshan Prefecture. Furthermore, we are very much indebted to Tang Liang 唐亮 for granting us permission to work in Zhaojue. We would also like to thank Li Xueyan 李雪燕 and Luo Jing 羅晶 for assisting us in interviewing, recording, and transcribing the resultant records. Last but not least, we are grateful to Kelly Fung and Alison Carter for carefully reading through and commenting on drafts of this paper.

\section{Notes}

1. Harrell, Ways of Being Ethnic, 65.

2. There is flat land fitting for agriculture near the Jinsha river in Leibo, Meigu, and Jinyang, for example, but these areas are largely dominated by Han.

3. Zeng, Daliangshan, 193.

4. Harrell and Li, "The History;" Harrell, Ways of Being Ethnic; "Ethnicity;" Cultural Encounter; Perspectives. Harrell has pointed out that the ethnic minority of the Yi as defined by the Chinese state contains a number of groups with very different and in some cases mutually unintelligible dialects, as well as significant differences in social structure, economic subsistence, customs, and dress. Nevertheless, all these groups share a common history and thus a sense of common identity that is best described by the exonym Yi.

5. There are six officially recognized Yi languages that are mutually unintelligible although they share a common writing system: Nuosu, Lalo, Lolopo, Nisu, Sani, and Nasu. Nuosu is most widely spoken and has been declared the official Yi language; Chen, Yizu shigao; Lama, Subgrouping. Nuosu is currently spoken by approximately two million people, $60 \%$ of them being monolingual; Nordhoff et al., "Sichuan Yi."

6. Schoenhals, Intimate Exclusion; Schoenhals, "The Sources." For a comparison to caste systems in other parts of the world see Fürer-Haimendorf 1966. 
7. Zhonggu, Sichuansheng Liangshan.

8. Harrell, Ways of Being Ethnic, 93-96.

9. Zhonggu, Sichuansheng Liangshan.

10. This information has been obtained through the interviews our team conducted in the Liangshan region in 2013. Similar observations have been made in Harrell, Ways of Being Ethnic, 91-95; Hill and Diehl, "A Comparative;" Lin, "Shilun dangdai;" Lin, The Lolo; Pan, "Shilun Liangshan."

11. Swancutt, "Fame."

12. Ma, Yizu gudaishi, 14-22; Harrell, Ways of Being Ethnic, 84.

13. Fang, Yizu shigao, 391.

14. Ma, Yizu gudaishi, 100-101.

15. Harrell, Ways of Being Ethnic, 85.

16. For a discussion of the Xifan mentioned in historic texts and their relationship with the presentday Prmi or Pumi, consult Harrell 2001a:63 ff.

17. Wu, "On the Nature." For further information on the Tusi system consult Took, A Native; Faure and Ho, Chieftains.

18. Ma, Yizu gudaishi, 106-107; Ma, Liangshan Luo, 75.

19. Fang, Yizu shigao, 556-560.

20. He, "Liangshan Tusi."

21. Ma, Yizu gudaishi, 109.

22. Sichuansheng and Zhongguo, Sichuansheng Liangshan, 87-89.

23. Zeng, Daliangshan, 117-127.

24. Ma, Liangshan Luo; Zeng, Daliangshan.

25. Zhu, "Minguo Liangshan."

26. This process has been described for example by Peter Goullart, Princes.

27. Ma, Liangshan Luo; Zeng, Daliangshan.

28. Ma, Liangshan Luo, 54-55.

29. Zeng, Daliangshan; Ma, Yizu gudaishi; Ma, Liangshan Luo; Sichuansheng and Zhongguo, Sichuansheng Liangshan.

30. Previously, Nuosu had already practiced agriculture but on a considerably smaller scale without the deforestation of large part of the mountainsides as induced by the Han settlers.

31. Quanguo, Liangshan Yizu, 181-182.

32. The Nuosu had a highly developed art of lacquer production and decoration as well as clothes production, but pottery making was not known to them and certain modern-day conveniences such as matches had to be imported from Han areas.

33. Ma, Liangshan Luo, 55-58; Zeng, Daliangshan, 184-186.

34. Ma, Liangshan Luo, 56.

35. Zeng, Daliangshan, 186.

36. Ma, Liangshan Luo, 58.

37. These 11 households included two from the $\mathrm{Li}$ 李 family, three from the $\mathrm{Mu}$ 母 family, two from the Huang 黃 family, and one each from the Cheng 程, Liu 劉, Hu 胡, and Zhang 張 families. Today, only the $\mathrm{Mu}, \mathrm{Li}$, and Zhang families are still represented by one or more households each (Sichuansheng and Zhongguo, Sichuansheng Liangshan, 158).

38. Liu, Cong shan.

39. Ma, Liangshan Luo; Zeng, Daliangshan; Lin, "Shilun dangdai;” Lin, The Lolo; Sichuansheng and Zhongguo, Sichuansheng Liangshan.

40. Bamo, Yiren; Harrell, Bamo, and Ma, Mountain Patterns; Ma, "Names and Genealogies;" Liu, Yizu shehui; Passage to Manhood; Ma, Yunnan yizu; Harrell, "Ethnicity, Local Interests;" Cultural Encounters; Ways of Being Ethnic; Perspectives; Heberer, Ethnic Entrepreneurs; Schoenhals, Intimate Exclusions; Schoenhals, "The Sources;" Hill and Diehl, "A Comparative." 
41. Harrell, Perspectives.

42. Ma, Liangshan Luo, 55-58.

43. For further information on Han masons and tool makers in Zhaojue, consult Quanguo, Liangshan Yizu.

44. Sichuansheng and Zhongguo, Sichuansheng Liangshan, 55-58.

45. Ibid., 180.

46. This rough calculation was made based on the change in the price of pork as a common staple. As we learned from various informants corroborating each other, currently bride prices can range between 10,000 and 200,000 RMB in the most extreme cases, so in the early 1970s, 400 RMB (i.e., the equivalent of 100,000 RMB) would have been a relatively high sum.

47. Apparently it was a little easier about 15-20 years ago when Ann Maxwell Hill conducted her research, but as no new slaves are taken the knowledge of the Han origin of the ancestors of people who self-identify as Nuosu at present is fading. Consult Hill, "Captives" for further examples.

48. Quanguo, Liangshan Yizu.

49. Sichuansheng and Zhongguo, Sichuansheng Liangshan, 180.

50. Schoenhals, "The Sources."

51. Ma, Liangshan Luo, 58; and Zeng, Daliangshan, 196-197.

52. Lin Yueh-hua, The Lolo, 90; Heberer, "Wirtschaft und Gesellschaft," 47.

53. Heberer, Ethnic Entrepeneurs; Heberer, Doing Business.

54. Sichuansheng and Zhongguo, Sichuansheng Liangshan, 179.

55. Similar observations on the diversity of the Han as a diverse group have been made in studies in other regions of China collected in Mullaney et al., Critical Han Studies.

56. Harrell, Ways of Being Ethnic, 95.

\section{Bibliography}

Bamo, A., Yiren De Xinyang Shijie: Liangshan Yizu Zongjiao Shenghuo Tianye Baogao. [The Yi world of belief: field reports on the religious life of the Yi of Liangshan]. Nanning: Guangxi Renmin Chubanshe, 2004.

Chen, K., Yiyu Fangyan Yanjiu. [Research on the Yi Dialect]. Beijing: Zhongguo Minzu Daxue Chubanshe, 2010.

Fang, G., Yizu Shigao. [History of the Yi Minority]. Chengdu: Sichuan Minzu Chubanshe, 1984.

Faure, D., and H. Ts'ui-p'ing. Chieftains into Ancestors: Imperial Expansion and Indigenous Society in Southwest China. Vancouver: UBC Press, 2013.

Fürer-Haimendorf, C. V. Caste and Kin in Nepal, India and Ceylon; Anthropological Studies in Hindu-Buddhist Contact Zones. Bombay; New York: Asia Publishing House, 1966.

Goullart, P. Princes of the Black Bone: Life in the Tibetan Borderland. London: J. Murray, 1966.

Harrell, S. "Ethnicity, Local Interests, and the State: Yi Communities in Southwest China." Comparative Studies in Society and History 32, no. 3 (1990): 515-548. doi:10.1017/ S0010417500016613.

Harrell, S. Cultural Encounters on China's Ethnic Frontiers. Seattle: University of Washington Press, 1995.

Harrell, S. Ways of Being Ethnic in Southwest China. Seattle and London: University of Washington Press, 2001.

Harrell, S., ed. Perspectives on the Yi of Southwest China, Studies on China. Vol. 26. Berkeley: University of California Press, 2001.

Harrell, S., B. Qubumo, and M. Erzi. Mountain Patterns: The Survival of Nuosu Culture in China. Seattle: University of Washington Press, 2000.

Harrell, S., and L. Yongxiang. "The History of the History of the Yi, Part II." Modern China 29, no. 3 (2003): 362-396. doi:10.1177/0097700403029003004. 
He, Y. “Liangshan Tusi Kaocha." [Survey on the Tusi of Liangshan]. Zhongguo Shehui Kexue 中國 社會科學 2 (1981): 95-102.

Heberer, T. Ethnic Entrepreneurs as Agents of Social Change: Entrepreneurs, Clans, Social Obligations and Ethnic Resources: The Case of Liangshan Yi in Sichuan. Duisburg: Institut für Ostasienwissenschaften, 2004.

Heberer, T. "Wirtschaft Und Gesellschaft." [Economy and Society]. In Chinas Volk Der Großen Kühlen Berge: Die Yi Gestern Und Heute [China's People of the Great Cool Mountains: The Yi Yesterday and Today], edited by Kultur- und Stadthistorisches Museum Duisburg, 46-51. Duisburg: Kultur- und Stadthistorisches Museum Duisburg, 2006.

Heberer, T. Doing Business in Rural China Liangshan's New Ethnic Entrepreneurs. Seattle: University of Washington Press, 2007.

Hill, A. M. “Captives, Kin, and Slaves in Xiao Liangshan." The Journal of Asian Studies 60, no. 4 (2001): 1033-1049. doi:10.2307/2700019.

Hill, A. M., and E. Diehl. "A Comparative Approach to Lineages among Xiao Liangshan Nuosu (Yi) and Han." In Perspectives on the Yi of Southwest China, edited by S. Harrell, 51-87. Berkeley: University of California Press, 2011.

Lama, Z. Q.-F. Subgrouping of Nisoic (Yi) Languages: A Study from the Perspectives of Shared Innovation and Phylogenetic Estimation. Saarbrücken: LAP Lambert Academic Publishing, 2013.

Lin, Y. "Shilun Dangdai Liangshanqu Dengji Guannian De Cancun Xingtai." [Discussion of Contemporary Remnants of Hierarchy in the Liangshan Region]. In Minzu, Zongjiao, Lishi Wenhua [Ethnic Group, Religion, and Cultural History], edited by Z. M. Xueyuan, M. Xi, and M. Yanjiusuo, 1-16. Beijing: Zhongyang Minzu Daxue Chubanshe, 1993.

Lin, Y.-H. The Lolo of Liang Shan. New Haven: Hraf Press, 1961.

Liu, H., Cong Shan Junling Zhong De "Lüzhou" - Anning Hegu Wenhua Yicun Diaocha Yanjiu. [An "Oasis" in between the Mountains - Research on the Cultural Relics of the Anning River Valley]. Chengdu: Bashu Shushe, 2009.

Liu, S.-H. Passage to Manhood: Youth Migration, Heroin, and AIDS in Southwest China. Stanford, Calif.: Stanford University Press, 2011.

Liu, Y., Yizu Shehui Lishi Diaoche Yanjiu Wenji. [Questions Concerning Field Research on the History of the Yi Social Groups]. Beijing: Minzu Chubanshe, 1980.

Ma, C., Yizu Gudaishi. [Ancient History of the Yi Minority]. Shanghai: Shanghai Renmin Chubanshe, 1987.

Ma, C., Liangshan Luo Yi Kaocha Baogao. [Report on Surveys on the Liangshan Luoyi]. Chengdu: Bashu Chubanshe, 2006.

Ma, E. "Names and Genealogies among the Nuosu of Liangshan." In Perspectives of the Yi of Southwest China, edited by S. Harrell, 81-93. Berkeley: University of California Press, 2001.

Ma, X., Yunnan Yizu Lisu Yanjiu Wenji. [Collection of Essays on Research of the Customs of the $\mathrm{Yi}$

People]. Chengdu: Sichuan Minzu Chubanshe, 1983.

Mullaney, T. S., J. Leibold, S. Gros, and E. V. Bussche, eds. Critical Han Studies: The History, Representation, and Identity of China's Majority. Berkeley and Los Angeles: University of California Press, 2012.

Nordhoff, S., H. Hammarström, R. Forkel, and M. Haspelmath, eds. "Sichuan Yi.” In Glottolog 2.2. Leipzig: Max Planck Institute for Evolutionary Anthropology, 2013. http://glottolog.org/

Pan, W. "Shilun Lianshan Yizu Nuli Shehui De Dengji Huafen." [Discussion on Social Stratification in the Slave-holder Society of the Yi Minority in the Liangshan Region]. In Xinnan Minzu Yanjiu: Yizu Zhuanji [Research on the Ethnic Groups of Southwest China: The Yi Minority], edited by Zhongguo Xinan Minzu Yanjiuhui, 321-324. Kunming: Yunnan Renmin Chubanshe, 1987. 
Quanguo Renmin Daibiao Dahui Minzu Weiyuanhui Bangongshi. Liangshan Yizu Zizhizhou Zhaojuexian Haoguxiang, Sikaixiang Shehui Diaocha. [Ethnographic Survey of Haogu Village and Sikai Village in Zhaojue County, Liangshan Yi Autonomous Prefecture]. Beijing: Quanguo Renmin Daibiao Dahui Minzu Weiyuanhui Bangongshi, 1957.

Schoenhals, M. Intimate Exclusion: Race and Caste turned Inside Out. Lanham, Md.: University Press of America, 2003.

Schoenhals, M. "The Sources of Ethnic Pride and Social Stability among the Nuosu (Yi) of Southwest China." In Continuity and Change in Cultural Adaptation to Mountain Environments, edited by L. R. Lozny, 341-360. New York, NY: Springer, 2013.

Sichuansheng Bianxiezu, and Zhongguo Shaoshu Minzu Shehui Lishi Diaocha Ziliao Congkan Xiuding Bianji Weiyuanhui. Sichuansheng Liangshan Yizu shehui lishi diaocha (zonghe baogao) [Survey on the History of the Liangshan Yi Minority (Final Report)]. Beijing: Minzu Chubanshe, 2009.

Swancutt, K. "Fame, Fate-Fortune, and Tokens of Value among the Nuosu of Southwest China." Social Analysis 56, no. 2 (2012): 56-72. doi:10.3167/sa.2012.560205.

Took, J. A Native Chieftaincy in Southwest China: Franchising a Tai Chieftaincy under the Tusi System of Late Imperial China. Leiden; Boston: Brill, 2005.

Wu, J. "On the Nature and Origins of the Nzymo." In Perspectives on the Yi of Southwest China, edited by S. Harrell, 35-48. Berkeley: University of California Press, 2001.

Zeng, Z., Daliangshan Yiqu Kaochaji. [Report of Surveys conducted in the Yi Area in the Greater Liangshan Region]. Beijing: Zhongguo Qingnian Chubanshe, 2012.

Zhongguo Shaoshu Minzu Shehui Lishi Diaocha Ziliao Congkan Xiuding Bianji Weiyuanhui. Sichuansheng Liangshan Yizu shehui lishi diaocha [Survey on the Historical Development of the Social Structure of the Liangshan Yi Minority in Sichuan]. Beijing: Minzu Chubanshe, 2009.

Zhu, Y. "Minguo Liangshan Diqu De Baotozhi Yanjiu." [Research on the Head-Protection System in the Liangshan Region during the Republican Period]. Dali Xueyuan Xuebao [Journals of the Dali Research Institute] 11, no. 1 (2012): 5-10. 